\title{
Effects of kelp canopies on understorey species due to shade and scour
}

\author{
Steven J. Kennelly* \\ Institute of Marine Ecology, Zoology A08, University of Sydney, 2006 Australia
}

\begin{abstract}
Mechanisms were investigated by which kelp canopies influence abundances of understorey species. First, the amount of shade afforded by kelp canopies and the frequency of scouring by kelp plants of various sizes were quantified. Next, the effects on understorey assemblages due to the reduction of light levels by kelp canopies were determined by manipulating the degree of shading in certain areas and comparing these with unmanipulated controls. Effects due to scouring by kelp laminae were determined by stopping scour in certain areas and comparing these with unmanipulated controls. Several treatments were included in these experiments to assess artifacts caused by the manipulations. Most species whose abundances changed after removing kelp (i.e. increases in filamentous and turfing algae, decreases in encrusting algae and ascidians), did not change in clearings where artificial shade was supplied. Scour by kelp plants showed no effects on most species, although the amount of sediment and microscopic silt were enhanced by stopping scour, as perhaps were the abundances of an anemone and an entoproct. The usefulness of field manipulations to test alternative hypotheses accounting for patterns detected in kelp communities is noted.
\end{abstract}

\section{INTRODUCTION}

Several recent papers have examined effects on kelp communities due to the removal of kelp canopies (Dayton et al. 1984, Reed \& Foster 1984, Santelices \& Ojeda 1984, Kennelly 1987 a, b, c). In these studies, changes in species composition and abundances have been attributed to changes in the light regime of the substratum caused by removal of the canopy. In my earlier papers (Kennelly 1987 a, b), I noted that the presence of an Ecklonia radiata (C. Agardh) J. Agardh canopy maintained an understorey assemblage of encrusting algae, sponges and bryozoans. When kelp was removed, filamentous and turfing algae dominated the substratum. In the present paper I consider the mechanisms by which the kelp canopy exerts such effects on these assemblages.

There are 3 main ways by which kelp plants may influence understorey species: by shading understorey species (Reed \& Foster 1984), by scouring understorey species (Black 1974, Velimirov \& Griffiths 1979), and/or

\footnotetext{
- Present address: Fisheries Research Institute, N.S.W. Agriculture \& Fisheries, PO Box 21, Cronulla, 2230, Australia
}

by exuding chemicals that affect understorey species (Fletcher 1974, Dayton et al. 1984). All, or any combination, of these may yield those results found in earlier clearance experiments.

The most obvious way kelp plants could affect understorey species is by changing the quantity and/or wavelengths of light (Dayton et al. 1984, Gerard 1984, Kimura \& Foster 1984, Reed \& Foster 1984). Certain filamentous and turfing algae are adapted to bright light and so flourish when kelp canopies are absent (Reed \& Foster 1984). Where a kelp canopy exists, only those species that can tolerate dim light will occur. In New South Wales kelp communities, these understorey species include encrusting algae, sponges and ascidians (Kennelly $1987 \mathrm{a}$, b). In previous experiments involving comparisons between areas with and without kelp canopies, effects due to light cannot be separated from any other effects of the presence of kelp (such as those due to scour or chemical exudation). In the present paper I examined the shading role of kelp canopies by experimentally imitating the shade provided by kelp plants and comparing these assemblages to assemblages under and away from natural canopies.

In addition to effects of shading, short, stipitate kelps also affect understorey species by scraping back and 
Table 1. Summary of experimental designs

\begin{tabular}{|c|c|c|c|c|c|}
\hline Expt. & Purpose & Treatments & Size and replication & Started & Duration \\
\hline 1 & $\begin{array}{l}\text { Effects of shading by } \\
\text { kelp canopies }\end{array}$ & $\begin{array}{l}\text { Natural canopy; cleared of kelp; } \\
\text { cleared \& shaded; cleared, co- } \\
\text { vered by plastic; cleared, shaded } \\
\& \text { plastic }\end{array}$ & $\begin{array}{l}\text { Two } 5 \times 5 \mathrm{~m} \text { sites, each } \\
\text { with } 2,40 \times 40 \mathrm{~cm} \text { reps. }\end{array}$ & Jan 1985 & $8 \mathrm{wk}$ \\
\hline 2 & $\begin{array}{l}\text { Effects of scouring by } \\
\text { kelp laminae }\end{array}$ & $\begin{array}{l}\text { Framed \& unframed areas in pre- } \\
\text { sence \& absence of short-stiped } \\
\text { kelps }\end{array}$ & $\begin{array}{l}\text { Two } 2 \times 2 \text { m sites, each } \\
\text { with } 3,30 \times 30 \mathrm{~cm} \text { reps. }\end{array}$ & Sep 1983 & $10 \mathrm{mo}$ \\
\hline
\end{tabular}

forth over the substratum. Whilst kelp laminae have been noted to affect understorey species by physical scouring in a previous study (Velimirov \& Griffiths 1979), there has been no experimental evaluation of this effect. This was done here by artificially removing kelp scour in certain areas of the forest, and comparing these to control areas where scour by kelp laminae was free to occur.

The effects of kelp plants on understorey species due to the exudation of chemicals has not received any attention, although other intertidal and subtidal algae are known to affect species by allelopathic influences (McLachlan \& Craigie 1966, Fletcher 1974, Carlson \& Carlson 1984). In clearances described elsewhere (Kennelly $1987 \mathrm{a}, \mathrm{b}$ ), healthy kelp plants were within $1 \mathrm{~m}$ of the centre of clearings and, if toxic influences occurred between kelp plants and benthic species, chemicals exuded from nearby kelps should reach the centres of clearings. From these results, I concluded that allelopathic effects of kelp plants in this particular kelp forest were possible but very unlikely. Treatments were nevertheless included in both experiments to isolate any overriding influences on understorey species due to chemical exudation.

\section{MATERIALS AND METHODS}

The study site was $4 \mathrm{~m}$ below low-tide level in a kelp forest in Fairlight Bay, Port Jackson, Sydney, Australia $\left(33^{\circ} 48^{\prime} \mathrm{S}\right.$; $\left.151^{\circ} 16.5^{\prime} \mathrm{E}\right)$. A description of the kelp forest in this area may be found in Kennelly (1983) and Kennelly (1987a). The kelp at Fairlight is the stipitate Ecklonia radiata.

The understorey assemblage in this kelp forest contains several types of encrusting algae, sponges, bryozoans, ascidians, and brown, red and green algae. Upon closer examination using an underwater microscope (Kennelly \& Underwood 1984), these assemblages also include diatoms, blue-green and other filamentous algae, juveniles of larger plants (including kelp) and microscopic animals (ostracods, amphipods, gastropods). Fine detritus and silt are found amongst these organisms. For a species list see Kennelly (1987b).

Experiment 1 - Effects on understorey species due to the reduction of light by kelp canopies (Table 1). As a means to test for effects on understorey species due to the shade afforded by kelp plants, structures were made which provided the same quantity of light that a kelp canopy provides. Replicate light readings were firstly taken under the kelp canopy, in natural clearings, and under various shading structures using a Licor (LI-188) quantum photometer. Under the natural canopy, $7.3 \pm 2.0 \mu \mathrm{E} \mathrm{m}^{-2} \mathrm{~s}^{-1}$ of light reached the substratum, compared to $140.2 \pm 1.7 \mu \mathrm{E} \mathrm{m}^{-2} \mathrm{~s}^{-1}$ in areas without a canopy. The structures that best mimicked the shade afforded by kelp canopies were covered by a double layer of shadecloth $\left(6.2 \pm 0.9 \mu \mathrm{E} \mathrm{m}^{-2} \mathrm{~s}^{-1}\right)$. Structures of $40 \times 40 \times 25 \mathrm{~cm}$ were then made of $20 \mathrm{~cm}$ mesh, $5 \mathrm{~mm}$ galvanised reinforcing steel to suspend this material $25 \mathrm{~cm}$ over the substratum (the approximate height of the natural canopy). Effects on species due to reducing light to the same levels as those under the kelp canopy were determined by comparing the abundances of species living under these structures with those living in clearings. Further, by comparing the abundances of species living under the canopy with those under shade-frames, I could isolate effects of the kelp canopy due to shade from those due to other factors (such as scour and/or the exudation of toxic chemicals).

Because these structures may affect understorey species in some way other than by reducing levels of light, artifacts due to these shade-frames were considered. There are 2 main artifacts of these frames: (1) they may alter the movement of water over the substratum; and/or (2) they may restrict the foraging of fish. Observations showed the latter to be negligible although 1 species (Meuschenia trachylepis (Gunther) - the local leather-jacket) cannot feed under the structures. Two additional treatments were included to test for artifacts. One was a shade-frame that had clear plastic over the frame instead of double shadecloth. This treatment allowed a similar amount of light through to the understorey species as that which occurs in areas with no 
Table 2. Summary of multiple regressions for the relationships between amount of scour and dimensions of surrounding kelp plants. Stipe length and lamina length are compared to the percentage of each tile wiped by kelp laminae over a 1 min period

\begin{tabular}{|c|c|c|c|c|c|c|}
\hline \multirow[t]{2}{*}{ Effect } & \multicolumn{3}{|c|}{ Rough seas } & \multicolumn{3}{|c|}{ Calm seas } \\
\hline & df & MS & F & df & MS & $\mathrm{F}$ \\
\hline Reduction due to stipes and laminae & 2 & 327.4 & $21.7^{*}$ & 2 & 118.7 & $9.5^{*}$ \\
\hline Reduction due to stipes after laminae & 1 & 296.8 & $19.7^{* *}$ & 1 & 201.8 & $16.2^{*}$ \\
\hline Reduction due to laminae after stipes & 1 & 12.9 & $0.9 \mathrm{~ns}$ & 1 & 7.1 & $0.6 \mathrm{~ns}$ \\
\hline Residual & 19 & 15.1 & & 17 & 12.6 & \\
\hline \multicolumn{7}{|l|}{$\cdot p<0.05$} \\
\hline \multicolumn{7}{|l|}{$\because p<0.01$} \\
\hline ns: not significant & & & & & & \\
\hline
\end{tabular}

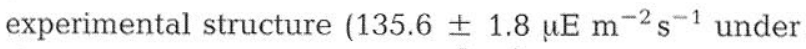
plastic versus $140.2 \pm 1.7 \mu \mathrm{E} \mathrm{m}^{-2} \mathrm{~s}^{-1}$ in clearings). Thus, any differences in abundances of species between this treatment and those in clearings are solely due to the frame in the presence of large amounts of light. Because this control of clear plastic formed a solid barrier to water flow, and the shadecloth treatments allowed some water to permeate, they may have caused different artifacts due to water flow. A second control was therefore included which had shading frames covered with both shadecloth and clear plastic. This treatment had little light getting through but also caused maximal disruption of water flow. By comparing the abundances of species in replicates of these 3 treatments (shadecloth, clear plastic, shadecloth with plastic), all artifacts due to the presence of the shading structures could be distinguished from their function of reducing light to those levels found under the canopy.

All treatments of this experiment were replicated in 2 large areas of kelp forest. All replicates were set up on 1 day. In both these areas I firstly cleared out all kelp in $5 \times 5 \mathrm{~m}$ squares. In these clearings I randomly placed 2 replicates of each of the 3 manipulated treatments (shadecloth, clear plastic, shadecloth with clear plastic), and 2 unshaded controls. Adjacent to each clearing were randomly located 2 unmanipulated replicates under the kelp canopy. Shade-frames were attached by concreting legs into holes drilled into the sandstone substratum, and by attaching galvanised guide wires down from the tops of the frames to small eyelets secured into the substratum. The understorey community was sampled macroscopically using two $15 \times 15 \mathrm{~cm}$, 100 -point quadrats in each replicate (using the pointintersect method). The relative abundances of microscopic organisms were also determined using a 9-point quadrat in an underwater microscope (Kennelly \& Underwood 1984) at a magnification of $53 \times$ (each field of view covered $5 \times 5 \mathrm{~mm}$ of substratum). Data for sessile microscopic species were recorded as the relative cover (out of a maximum of 9 points) and micro- scopic animals were recorded as the total number in each quadrat. Ten such quadrats were sampled in each replicate in this experiment. Macroscopic and microscopic organisms were identified as accurately as possible in the field and samples were collected for further identification in the laboratory. The experiment was sampled initially, and then 2, 4,6 and 8 wk later. After this time, the species assemblage under the shading structures was influenced by the encroachment of filamentous and turfing algae from surrounding, unshaded areas.

Experiment 2 - Effects on understorey species due to scour by kelp plants (Table 1). The relative amount of scour that occurred on understorey species at Fairlight under kelps of various dimensions was determined. White, glazed, $150 \times 150 \mathrm{~mm}$ bathroom tiles were painted with a thin coat of red, water-soluble paint. When underwater, this paint was wiped off the tile at the slightest touch. On a day with a moderate swell in the bay, and again on a day with a low swell, 20 tiles were randomly placed under the kelp canopy for 1 min periods. After this, the percentage cover of white on each tile (that area which had been touched by kelp laminae) was recorded. Stipe and lamina lengths of those kelp plants in the immediate vicinity of each tile were measured. The relationships between the dimensions of kelp plants and the amount of scour by such plants were quantitatively determined in a multiple regression analysis (Table 2). This analysis revealed no significant relationship between the amount of scour by kelp laminae and the length of these laminae. The amount of scour was strongly correlated with the length of stipes: more scour occurred in areas of the forest with short-stiped plants than in areas surrounded by long-stiped plants (Table2, Fig. 1). Further, this effect was more pronounced on a day with rough seas than on a day with calm seas (for details of the swell conditions at the site see Kennelly 1987a).

To determine effects on understorey species due to scour by kelp laminae, scouring was stopped in certain 


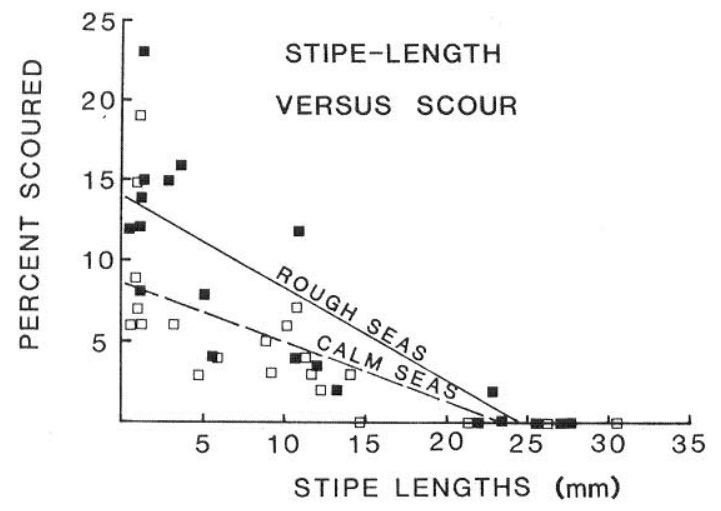

Fig. 1. Regressions between scour of substratum by kelp plants and stipe length of these plants, on days with calm

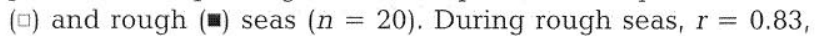
$\mathrm{df}=18, p<0.001$; during calm seas, $r=0.70$, $\mathrm{df}=18, p<0.05$

areas and compared to areas where scour occurred. Because it was found that short-stiped kelp plants were responsible for most of the scour done by laminae on understorey species, only areas with short-stiped plants were used.

To stop kelp laminae from touching the substratum, $30 \times 30 \times 2 \mathrm{~cm}$ frames were made from $100 \mathrm{~mm}$ mesh, $6 \mathrm{~mm}$ galvanized reinforcing steel and attached to the substratum under the kelp canopy by concreting the legs of each frame into holes drilled in the substratum. These frames effectively stopped laminae from touching the substratum and still permitted access to fish and invertebrates.

Control treatments were included to assess any effects of the presence of these frames other than their function of stopping scour. The best way to control for artifacts on understorey species due to these frames would be to compare the assemblages in framed and unframed areas in both the presence and absence of scour. In such comparisons, any differences between framed and unframed areas would be due to the presence of the frames themselves and not due to effects of scour. Unfortunately, it is impossible to compare framed and unframed areas that are also scoured by kelp plants (the former control), because the frames (by intention) stop scour. It is possible, however, to compare framed and unframed areas in places where scouring is restricted in some other way (the latter control). The most effective way to stop scouring by kelp laminae (apart from using frames) is to remove those plants which do the scouring (i.e. short-stiped plants). I therefore removed all short-stiped plants from areas and compared framed and unframed replicates inside such areas. Both treatments therefore should have had no scour, but only one treatment had frames present. This determined the effects on understorey species due to the presence of the frames in the absence of scour. A problem with this control is the possibility that removing short-stiped plants affects the understorey community in some way other than by stopping scour, e.g. by increasing the levels of light under the canopy. This was found not to occur because these short plants were not part of the overlying canopy and so their removal had little effect on quantities of light $\left(6.9 \pm 1.6 \mu \mathrm{E} \mathrm{m} \mathrm{m}^{-2} \mathrm{~s}^{-1}\right.$ before removal of short plants versus $7.3 \pm 2.0 \mu \mathrm{E} \mathrm{m} \mathrm{m}^{-2}$ $\mathrm{s}^{-1}$ after manipulation) and such small changes in light levels do not affect abundances of understorey species (Kennelly 1987b). A test for these potential artifacts was nevertheless included by comparing framed replicates from areas with and without short-stiped plants. Both these treatments have no scour and a frame present, but only one treatment is in the absence of small kelps. Thus, any differences between these 2 treatments will be due to the removal of short plants and not due to scouring by kelps.

By comparing the abundances of understorey species living in the various treatments described above, I could isolate any artifacts due to the frames in the absence of scour. By comparing areas under and away from frames in parts of the forest with many shortstiped plants (and hence much scouring), I could accurately determine effects on understorey species due to scour by these kelps. This experiment was set up in September 1983 and was macroscopically and microscopically sampled initially, and then $2,4,6,8,10,14$, $16,20,24,32$ and $40 \mathrm{wk}$ later.

In both experiments, data for all species (recorded macroscopically and microscopically) were analysed by tests for homogeneity of variances, the relevant 3-factor analysis of variance and Student-Newman-Keuls multiple comparisons (significance level of $p=0.05$ ). Those sets of data that showed significant variation among experimental treatments are discussed below.

\section{RESULTS}

The results from the 2 experiments are summarized in Table 3.

\section{Experiment 1 - Effects of shading by kelp canopies}

More of the encrusting algae Peyssonelia/Hildenbrandia complex occurred in shaded areas than in unshaded areas (both under and away from frames covered by clear plastic) after 4 wk (Fig. 2a). The covers of Peyssonelia/Hildenbrandia complex under shaded areas did not differ from those under the natural canopy for the first $4 \mathrm{wk}$. After $8 \mathrm{wk}$, the cover of these algae under treatments with shadecloth decreased compared to areas under the natural canopy, and those 
A Peyssonelia/Hildenbrandia
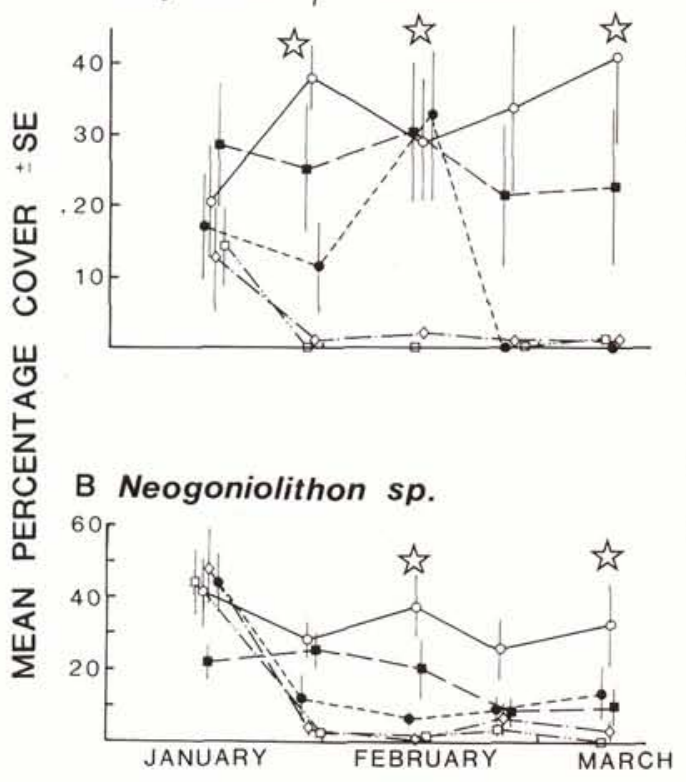

C Didemnum sp.

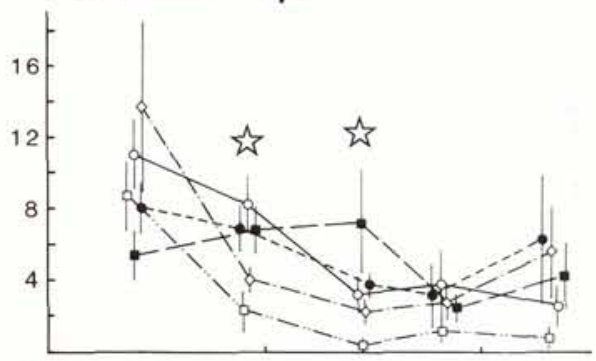

D Myxilla sp.

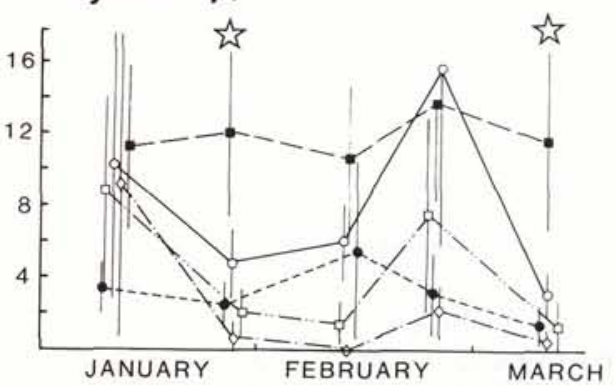

Fig. 2. Effects due to manipulating light levels on the covers of (A) Peyssonelia/Hildenbrandia complex; (B) Neogoniolithon sp.; (C) Didemnum sp.; (D) Myxilla sp. Treatments: areaš cleared of kelp with no shading structures $(\diamond)$; areas under natural kelp canopy ( $(\circ)$; areas cleared of kelp and covered by shade-frame with shadecloth $(\bullet)$; areas cleared of kelp and covered by shadeframe with clear plastic $(\square)$; areas cleared of kelp and covered by shade-frame with shadecloth and clear plastic $(\mathbf{m}) ; n=8$. In this and subsequent figures, $\&$ denotes a significant difference among plotted means determined in the analysis of variance of the data and SNK comparisons at that time of sampling

under both shadecloth and clear plastic. In the shortterm, at least, reduction of light in clearings maintained the great covers of Peyssonelia/Hildenbrandia complex that were found under the kelp canopy. After $6 \mathrm{wk}$ in this experiment, however, the covers of these encrusting algae may have been influenced by artifacts of the experiment - seen later to be the encroachment of sediment and turfing algae into shaded areas from unshaded areas.

There was significantly more of the encrusting alga Neogoniolithon sp. in areas under the natural canopy and under the treatments with both shadecloth and plastic than in other treatments after $4 \mathrm{wk}$ (Fig. 2b). Because there were no differences between shaded and unshaded areas in clearings, no effects due to the reduction of light can be inferred. Similarly, after $8 \mathrm{wk}$, there were no consistent results to suggest reduced light levels enhanced the growth of this alga.

The cover of the compound ascidian Didemnum sp. decreased in unshaded areas after $2 \mathrm{wk}$ (Fig. 2c). This occurred both in the open and under frames covered by clear plastic - indicating no artifacts due to the frames. In replicates under the canopy and under shaded structures, the cover of Didemnum sp. remained large for $2 \mathrm{wk}$, and for the treatment with shadecloth and plastic, abundances remained large for $4 \mathrm{wk}$. There were no differences among any of the treatments after this time.
The sessile sponge Myxilla sp. was significantly more abundant under the shadecloth and plastic treatments than any other treatment after $2 \mathrm{wk}$ and again after $8 \mathrm{wk}$ (Fig. 2d). Because no such increase occurred in areas under shadecloth only, no effects on the cover of Myxilla sp. due to the reduction of light can be inferred.

The cover of the brown turfing algae Zonarial Lobophora complex remained small in treatments under shade and not significantly different from areas under the natural canopy after $4 \mathrm{wk}$ (Fig. 3a). The cover of these algae therefore increased as a result of the increased levels of light reaching the substratum in clearings. After $6 \mathrm{wk}$, there were no significant differences between any of the treatments.

The cover of another turfing alga, Dictyota dichotoma (Hudson) Lamouroux, increased after $4 \mathrm{wk}$ in areas without shading (Fig. 3b). This species also increased in areas under clear plastic indicating no artifacts due to the frames. $D$. dichotoma remained sparse under all shaded treatments and under the canopy. Large amounts of light therefore increased the cover of this species.

A layer of sediment (a conglomerate of micro-algae, micro-invertebrates and microscopic silt) eventually built up in all treatments in clearings, regardless of shading (Fig. 3c). The exception was in the treatment with both shadecloth and plastic. This treatment main- 

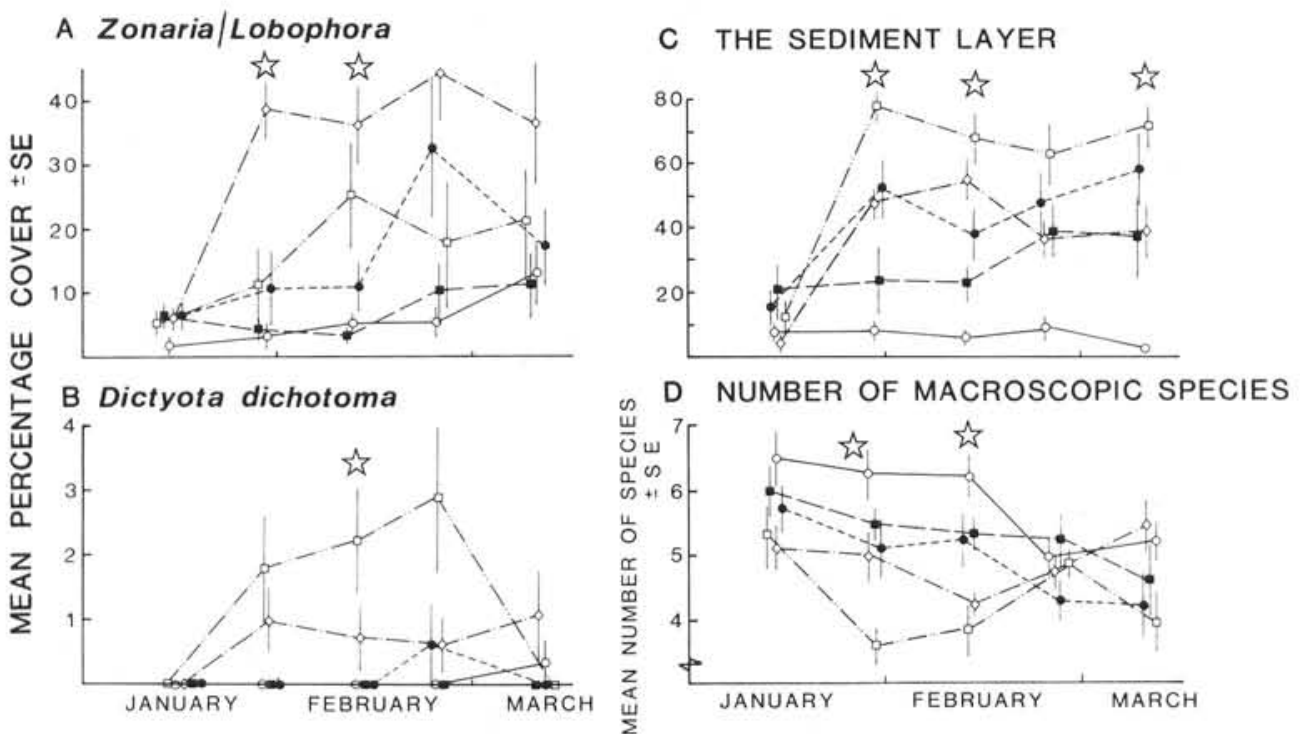

Fig. 3. Effects due to manipulating the levels of light on the covers of (A) Zonaria/Lobophora complex; (B) Dictyota dichotoma; (C) layers of sediment; (D) number of species sampled macroscopically. For explanation of symbols, see legend to Fig. 2

tained a small abundance of sediment for $4 \mathrm{wk}$. After $4 \mathrm{wk}$, the sediment layer had increased under unshaded areas so that these treatments had more sediment than shaded areas. All treatments in clearings eventually had great covers of the sediment layer compared to areas under the natural kelp canopy. For 4 wk therefore, shading seemed to keep the cover of the sediment layer smaller than that in totally unshaded areas. Encroachment by sediment into shaded treatments influenced results after 6 to $8 \mathrm{wk}$.

The number of species sampled in macroscopic quadrats decreased in areas covered by clear plastic after $2 \mathrm{wk}$, and in open areas after $4 \mathrm{wk}$ (Fig. 3d). The number of species remained great in shaded areas and in areas under the kelp canopy. Reduction of light therefore maintained a greater species richness than that in areas with high levels of light for at least $4 \mathrm{wk}$.

The cover of unicellular algae (sampled microscopically) showed no significant effects due to different levels of light (Fig. 4a). There was a non-significant trend, however, where unicellular algae increased in all those treatments in clearings, regardless of the amount of shade.

After $2 \mathrm{wk}$ the abundances of the filamentous microscopic alga Enteromorpha intestinalis (Linnaeus) Link increased in those areas without shading compared to shaded areas and areas under the canopy (Fig. 4b). After this time E. intestinalis decreased in cover. This indicated that the amount of light initially increased the abundance of this species.

The cover of microscopic silt showed a significant difference among treatments in February but there were no significant differences among these means using SNK tests. There was a non-significant trend for more microscopic silt to occur in treatments in clearings compared to areas under the canopy (Fig. 4c). No effects due to light were in evidence.

\section{Experiment 2 - Effects of scour by kelp laminae}

There was a significant trend for the cover of Peyssonelia/Hildenbrandia complex to decrease in all treatments in the experiment examining effects of scour (Fig. 5a). This decrease occurred first in framed areas in the presence of short-stiped kelps (i.e. those plants that scoured the substratum). After $5 \mathrm{mo}$, these encrusting algae increased in replicates without frames and decreased in replicates with frames in the presence and absence of short kelps. This indicated that the frames had a negative effect on the cover of Peyssonelia/Hildenbrandia complex in the presence and absence of short kelps.

The compound ascidian Didemnum sp. showed a significant difference between treatments in November, but there were no significant differences among these means using SNK tests. There was a nonsignificant trend after 5 mo with more Didemnum sp. in all treatments except those unframed in the absence of short-stiped kelps (Fig. 5b). No effects due to scour can be inferred from this result.

The cover of the anemone Cnidopus verater (Drayton) increased after $8 \mathrm{wk}$ in those treatments with frames that stopped scour, in the presence of short- 


\section{A UNICELLULAR ALGAE}

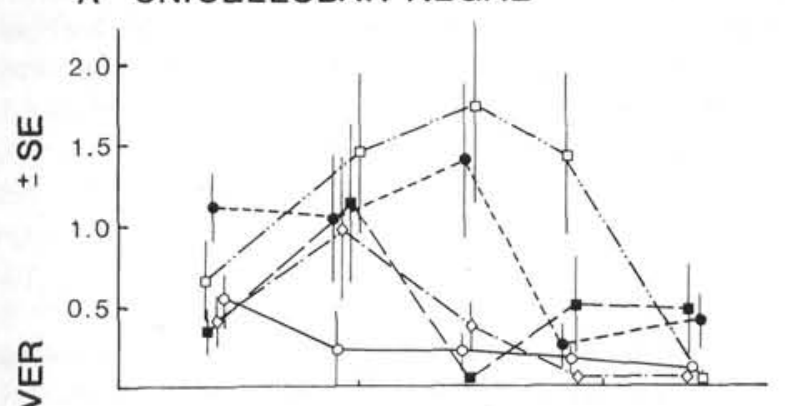

B Enteromorpha intestinalis

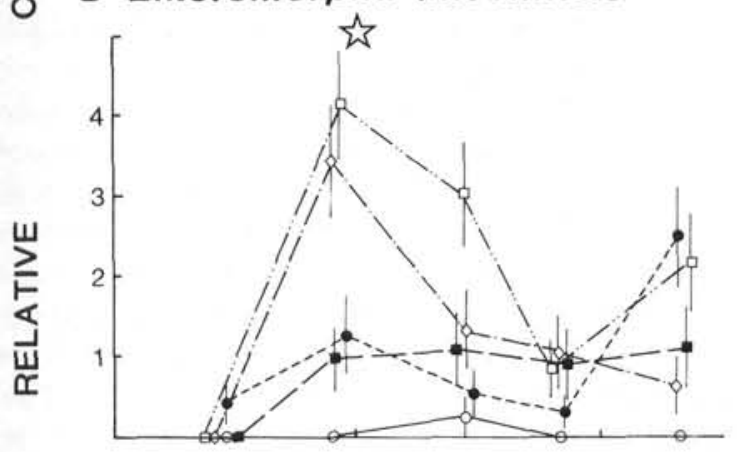

C MICROSCOPIC SILT

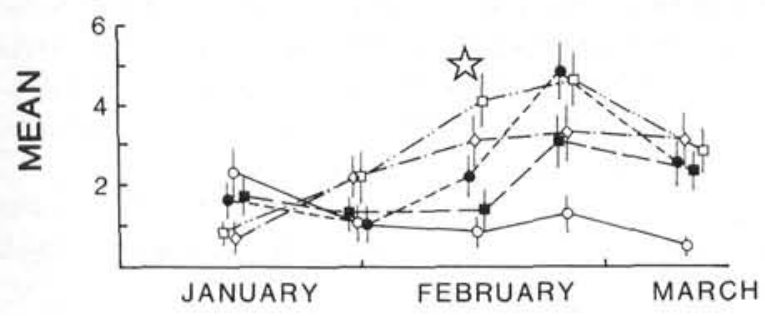

Fig. 4. Effects due to manipulating the levels of light on the covers of (A) unicellular algae; (B) Enteromorpha intestinalis; (C) microscopic silt; $n=32$. For explanation of symbols, see legend to Fig. 2

stiped kelps (Fig. 5c). No such increases occurred in other treatments - i.e. areas scoured by short kelps and areas without short-stiped plants maintained small numbers of $C$. verater. Thus, in areas where there were short plants, the removal of scour by frames seemed to attract $C$. verater. No artifacts due to the frames were in evidence because there was no significant difference between framed and unframed areas in the absence of short kelps.

For the cover of the sediment layer, there was a significant interaction after $4 \mathrm{wk}$ between the presence or absence of short kelps and the presence or absence of a frame to stop scour (Fig. 5d - analysis of variance $p<0.05$ ). That is, there was more of the sediment layer in framed areas in the presence of short kelps than in the other 3 treatments. This indicated that the presence of short plants facilitated a build up of sediment, but this increase was negated in such areas by scouring by laminae of these short kelps.

There were more unicellular algae after $8 \mathrm{mo}$ in areas with frames compared to unframed areas (Fig. 6a). This occurred both in the presence and absence of shortstiped plants indicating some artifact of the frames enhancing the survival of these algae at this time.

There was a non-significant increase after $2 \mathrm{wk}$ in the cover of the microscopic entoproct Pedicellina sp. in all those treatments without kelp scour - i.e. in framed areas in the presence of short kelps, and in framed and unframed replicates at sites without short-stiped plants (Fig. 6b). After $6 \mathrm{mo}$ there were more of this species in treatments without short-stiped kelps than in those

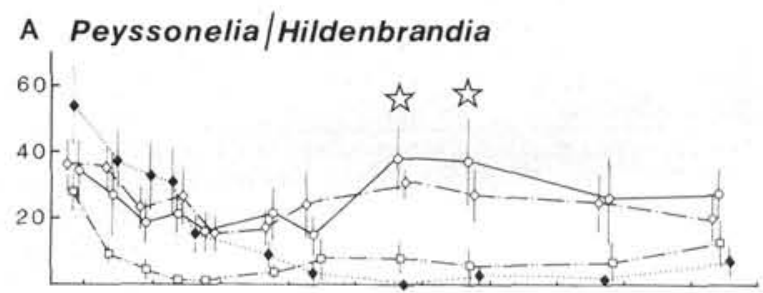

๗
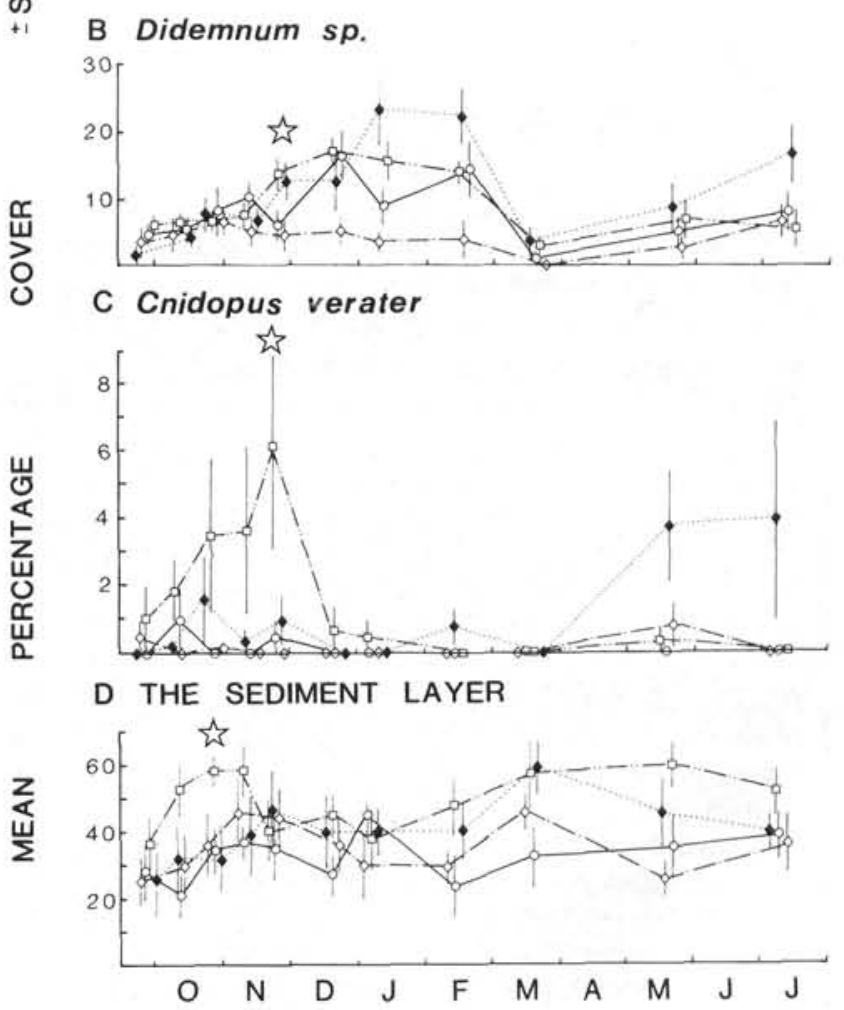

Fig. 5. Effects due to manipulating the amount of scour by kelp plants on the covers of (A) Peyssonelia/Hildenbrandia complex; (B) Didemnum sp.; (C) Cnidopus verater; (D) layjers of sediment. Treatments: areas under scouring kelps $(\circ)$; areas in presence of scouring kelps, covered by a frame which stops scour (a); areas without scouring kelps $(\diamond)$; areas without scouring kelps covered by a frame which stops scour $(\bullet) ; n=6$ 
treatments with short plants but SNK tests showed no significant differences among these means.

After $2 \mathrm{wk}$ and again after $8 \mathrm{wk}$, there was significantly more microscopic silt in framed areas in the presence of short-stiped plants than in unframed areas

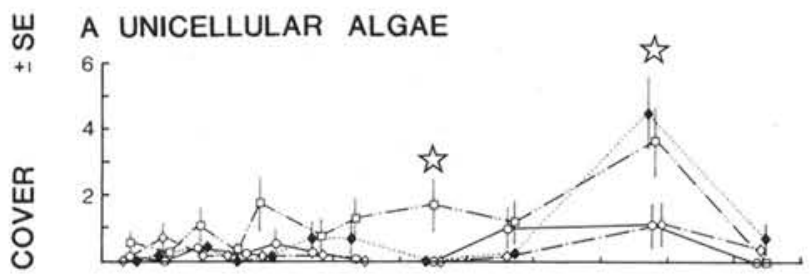

\section{B Pedicellina sp.}

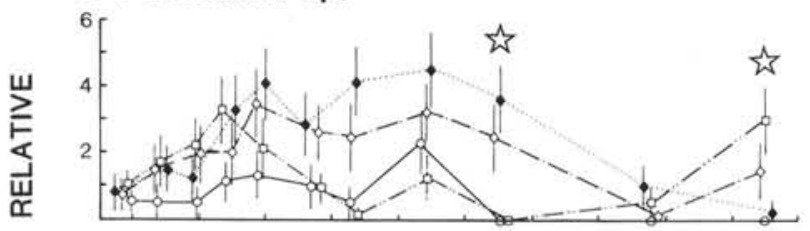

C MICROSCOPIC SILT

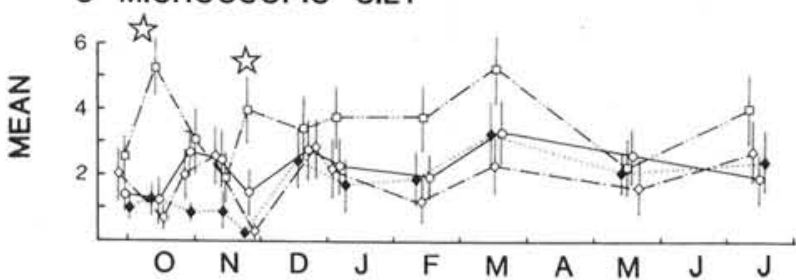

Fig. 6. Effects due to manipulating the amount of scour by kelp plants on the covers of (A) unicellular algae; (B) Pedicellina sp.; (C) microscopic silt; $n=24$. For explanation of symbols, see legend to Fig. 5
(Fig. 6c). No such increase occurred in areas without short-stiped plants. This showed that fine silt was not attracted to areas without small plants, but was attracted to areas with small plants when scour by such plants was prevented.

\section{DISCUSSION}

The presence of the kelp canopy at Fairlight affected some understorey species by providing shade. For other, more uncommon species, scouring by kelp laminae may have affected abundances. These results are summarized in Table 3.

In the experiment to test for effects of the canopy reducing the amount of light, several species showed trends consistent with the fluctuations seen in clearance experiments in Kennelly $(1987$ a, b, c). As in previous experiments, Peyssonelia/Hildenbrandia complex and Didemnum sp. decreased in clearings as filamentous algae (Enteromorpha intestinalis) and turfing algae (Zonaria/Lobophora complex and Dictyota dichotoma) increased in cover. Simultaneously, sediment increased in clearings and the species richness of the assemblage decreased. These effects did not occur in clearings where artificial shade was provided, indicating that these changes in the structure of the understorey community occurred because of the increased levels of light reaching the substratum.

A problem with this experiment was the occurrence of artifacts due to the experiment design. These

Table 3. Summary of results for effects of shading and scour by kelp plants on abundances of understorey species. Time after manipulation at which an increase $(+)$ or decrease $(-)$ occurred given in weeks $(\mathrm{w})$ or months (m). Timing of frame artifacts due to the manipulations is also given

\begin{tabular}{|c|c|c|c|c|c|}
\hline \multirow[b]{2}{*}{ Taxon } & \multicolumn{3}{|c|}{$\begin{array}{c}\text { Expt } 1 \\
\text { Effects of light }\end{array}$} & \multicolumn{2}{|c|}{$\begin{array}{c}\text { Expt } 2 \\
\text { Effects of scour }\end{array}$} \\
\hline & $\begin{array}{l}\text { In the } \\
\text { open }\end{array}$ & $\begin{array}{l}\text { Under } \\
\text { shade }\end{array}$ & Artifacts & $\begin{array}{l}\text { Scoured } \\
\text { areas }\end{array}$ & Artifacts \\
\hline Peyssonelia/Hildenbrandia & $-4 \mathrm{w}$ & ns & $\cdot 6 \mathrm{w}$ & ns & $\cdot 5 \mathrm{~m}$ \\
\hline Neogoniolithon sp. & ns & ns & ns & ns & ns \\
\hline Didemnum sp. & $-2 \mathrm{w}$ & ns & ns & ns & ns \\
\hline Myxilla sp. & ns & ns & ns & ns & ns \\
\hline Zonaria/Lobophora & $+2 \mathrm{w}$ & ns & ns & ns & ns \\
\hline Dictyota dichotoma & $+4 \mathrm{w}$ & ns & ns & ns & ns \\
\hline Enteromorpha intestinalis & $+2 \mathrm{w}$ & ns & ns & ns & ns \\
\hline Cnidopus verater & ns & ns & ns & $-8 \mathrm{w}$ & ns \\
\hline Pedicellina sp. & ns & ns & ns & $-2 \mathrm{w}(\mathrm{ns})$ & $\cdot 6 \mathrm{~m}$ \\
\hline Unicellular algae & ns & ns & ns & ns & $\cdot 8 \mathrm{~m}$ \\
\hline Sediment layer & $++2 w$ & $+4 \mathrm{w}$ & $\cdot 6 \mathrm{w}$ & $-4 w$ & - short plants \\
\hline Microscopic silt & ns & ns & ns & $-2 w,-8 w$ & 'short plants \\
\hline Species richness & $-2 w$ & ns & ns & ns & ns \\
\hline
\end{tabular}


artifacts involved encroachment by sediment layers and turfing algae after about $6 \mathrm{wk}$ from unshaded areas into manipulated areas. Because of these influences, longer-term effects of light reduction could not be inferred. Future experiments along these lines should use larger shading structures (around $2 \times 2 \mathrm{~m}$ ), each placed in their own area within a kelp forest. Despite this problem, this experiment showed that, at least during the first month after removing kelp, changes in the abundances of most species are a result of changes in levels of light and are not due to some other influence of the kelp.

Scouring by kelp laminae was found to have very few effects on the abundances of species in the kelp forest. Those species which showed changes in abundances following removal of kelp (encrusting species, filamentous and turfing algae) showed no such changes following the removal of scour. Two fairly uncommon species, the anemone Cnidopus verater and the microscopic entoproct Pedicellina sp., did seem to prefer living in areas without scouring laminae.

The sediment layer and the cover of microscopic silt showed 2 different effects in the experiment testing for effects of scour. First, the settlement of sediment and silt occurred to a greater extent in areas with shortstiped kelps than in areas without short kelps (evidenced by sediment build-up under frames in these areas). This was possibly due to enhanced entrapment of sediment into areas which had a structurally-complex substratum, provided by the holdfasts of small kelps. Second, scouring plants decreased the sediment and fine silt which settled in such areas - probably by repeatedly 'sweeping' the sediment off the substratum (evidenced by reduced sediment away from frames in these areas). The consequences of these 2 opposing effects of short kelps are that the potential build-up of sediment in areas with small kelps does not normally occur. By artificially stopping scour in these areas I was, however, able to show the attraction of sediment and silt into areas with small kelps. Artifacts due to the presence of the frames were found to influence the results for Pedicellina sp. after $6 \mathrm{mo}$, and for unicellular algae after $8 \mathrm{mo}$. Also, as discussed above, artifacts due to the removal of short-stiped kelps in control areas could have affected the results for sediment and fine silt.

Despite some problems with the above experimental designs, new information on the dynamics between kelp plants and their understorey community was obtained. Most of the changes observed in clearance experiments in this kelp bed were found to be due to changes in the levels of light caused by the canopy. A similar conclusion has often been made in previous studies involving kelp clearances (Dayton et al. 1984, Reed \& Foster 1984, Santelices \& Ojeda 1984). Other effects of the kelp canopy due to scour were found to be negligible for most species although an entoproct and and anemone seemed to be more common in areas protected from scouring by kelps. The cover of sediment and silt was reduced by scour, increased in the presence of short-stiped kelps, and increased in clearings with increased light. The latter probably occurred due to changes in the abundances of filamentous and turfing algae which facilitated the entrapment of sediment and fine silt in clearings.

It was possible to separate and test alternative hypotheses to account for the effects observed in clearance experiments in kelp forests using manipulative field experiments. The results showed that such procedures are extremely useful in determining details of the ecology of kelp forests.

Acknowledgements. This study was part of a $\mathrm{Ph}$. D. project funded by a University of Sydney Post-graduate Research Award and funds from the University of Sydney Research Grant. I sincerely thank Dr A. J. Underwood for his assistance at most stages of this research. I also thank Professors M. S. Foster, J. H. Choat, P. K. Dayton and J. Pearse for helpful comments. I am especially grateful to G. Graf, C. Gray, J. Murray, P. Scanes, and P. Kennelly for assistance with field work.

\section{LITERATURE CITED}

Black, R. (1974). Some biological interactions affecting intertidal populations of the kelp Egregia laevigata. Mar. Biol. 28: $189-198$

Carlson, D. J., Carlson, M. L. (1984). Reassessment of exudation by fucoid macroalgae. Limnol. Oceanogr. 29: 1077-1087

Dayton, P. K., Currie, V., Gerrodette, T., Keller, B. D., Rosenthal, R., ven Tresca, D. (1984). Patch dynamics and stability of some California kelp communities. Ecol. Monogr. 54: 253-289

Fletcher, R. L. (1974). Heteroantagonism observed in mixed algal cultures. Nature, Lond. 253: 534-535

Gerard, V. A. (1984). The light environment in a giant kelp forest: influence of Macrocystis pyrifera on spatial and temporal variability. Mar. Biol. 84: 189-195

Kennelly, S. J. (1983). An experimental approach to the study of factors affecting algal colonization in a sublittoral kelp forest. J. exp. mar. Biol. Ecol. 68: 257-276

Kennelly, S. J. (1987a). Physical disturbances in an Australian kelp community. I. Temporal effects. Mar. Ecol. Prog. Ser. 40: $145-153$

Kennelly, S. J. (1987b). Physical disturbances in an Australian kelp community. II. Effects on understorey species due to differences in kelp cover. Mar. Ecol. Prog. Ser. 40: 155-165

Kennelly, S. J. (1987c). Inhibition of kelp recruitment by turfing algae and consequences for an Australian kelp community. J. exp. mar. Biol. Ecol. 112: 49-60

Kennelly, S. J., Underwood, A. J. (1984). Underwater microscopic sampling of a sublittoral kelp community. J. exp. mar. Biol. Ecol. 76: 67-78

Kimura, R. S., Foster, M. S. (1984). The effects of harvesting Macrocystis pyrifera on the algal assemblage in a giant kelp forest. Hydrobiologia 116: 425-428 
McLachlan, J., Craigie, J. S. (1966). Antialgal activity of some simple phenols. J. Phycol. 2: 133-135

Reed, D. C., Foster, M. S. (1984). The effects of canopy shading on algal recruitment and growth in a giant kelp forest. Ecology 65: 937-948

Santelices, B., Ojeda, F. P. (1984). Effects of canopy removal on the understorey algal community structure of coastal forests of Macrocystis pyrifera from southern South America. Mar. Ecol. Prog. Ser. 14: 165-173

Velimirov, B., Griffiths, C. L. (1979). Wave-induced kelp movement and its importance for community structure. Botanica mar. 22: 169-172

This article was submitted to the editor; it was accepted for printing on September 19, 1988 